\title{
ADOLF ETHOLÉN AND ERNEST ERICKSON
}

\author{
The Founders of the North American Indian \\ Collections in the National Museum of Finland
}

Anne Aurasmaa

In Finland cultural studies, like sociology and anthropology, has played an important part nationally and even internationally in the studies of non-material forms of cultures of foreign nations. On the other hand, the study of material cultures has been neglected for the most part. This situation is only natural, as the links between collections, museums and universities, necessary for the education of material culture researchers, are only now being forged after a hiatus of many years. This separation was the result of various events, beginning with the cessation of Russian funding after Finland became independent in 1917 and becoming more serious with the rejection of material cultures in the 1960s linked with the rise of social anthropology. Fashions in research come and go, and today there are other ways of doing anthropological research besides fieldwork in some contemporary community or culture. The historical formation of cultures and the vast amount of documentation already available can once again be considered interesting.

In Europe, museology as an independent discipline has been part of the curriculum since the 1960s. Establishing this particular field of study can be seen as part of the growing interest in sociological studies of cultures. Functioning as a kind of a turning point, the 1983 congress on the subject of The Cabinet of Curiosities in the Ashmolean Museum in Oxford awakened an interest in the study of the oldest collections. Since then, museum collections have grown in importance as objects of study, and during the last 10 ? 15 years many inventories and reconstructions have been made of the museums, kunstkammers and curiosity cabinets of old. Part of this trend is the publication of new catalogues with up-to-date information to the pleasure of both researchers and the general public, as most of the material, especially that in cultural historical museums, is very rarely exhibited.

The ethnographic collection («Exotica») of the National Museum of Finland is a representative example of its type. It is one of the least known in Europe, because 
only a few catalogues of its collections have ever been available. In the course of the 1990s this situation has been redressed, at least for those interested in North American cultures. The work of the explorers and collectors has been made available to the general public by such means for example as the Matka-arkku ('Traveller's Trunk') an exhibition put on by the Museum of Applied Arts in 1989 in Helsinki. An award winning book accompanied this exhibition but unfortunately is only available in Finnish. Some specific and important groups of Exotica-objects have also been studied and published, but most interesting for the material culture studies are the books The Etholén Collection (1990) and Taku Wakan (1995). This is because, in picturing two collections in their entirety, both the collectors and the values of the periods when the collections were made can be observed through the material.

\section{EXOTICA AND ADOLF ETHOLENN WITH CONTEMPORARIES}

The Finnish National Museum has North American artefacts in the Etholén Collection (items from Alaska) and the Erickson Collection (representing almost all North American cultural areas). The museum also has an important archaeological Mesa Verde Collection by Nordenskiöld and small exchange collections from The Denver Art Museum and The Peabody Museum. There are also some independent objects which have been donated to the museum or otherwise acquired.

The Age of Enlightenment and the natural history studies of the 18 th century created an interest in the idea of accumulating objects to form study collections for the universities. During the 19th century this led to the birth of ethnological reference collections in Finland as well as all around Europe. In Finland this happened even before domestic ethnographical material was systematically collected.

Following the German humanist tradition, Peter the Great founded a museum in 1714 in St. Petersburg. It was opened to the public five years later. The most important purpose of the museum was to educate the general public, but Peter the Great also wanted to promote the development of Russian science. He bought objects, united old collections of the former tsars and also sent expeditions to collect new material. When Sweden lost Finland to Russia in 1809, Finland got her share of the Russian empire's active science policy and expeditions. The work of Adolf Etholén (1799-1876) and his contemporaries collecting in Alaska belong to this era. Of course, during the 19th century in Finland, an even stronger scientific trend was the study of languages, the origins and conditions of the Fenno-Ugrian nations of Europe and Siberia. It was through this study that Finns started to develop their own national identity.

In 1818 Adolf Etholen docked at Sitka in Alaska for the first time and there signed the five-year agreement with the Russian-American Company, thereby committing himself to service in the colonies. His long career as an officer led him to be the de facto governor general of Alaska when he was appointed overall manager by the company in 1838 .

During this time, the scientific paradigm was belief in the theory of cultural 


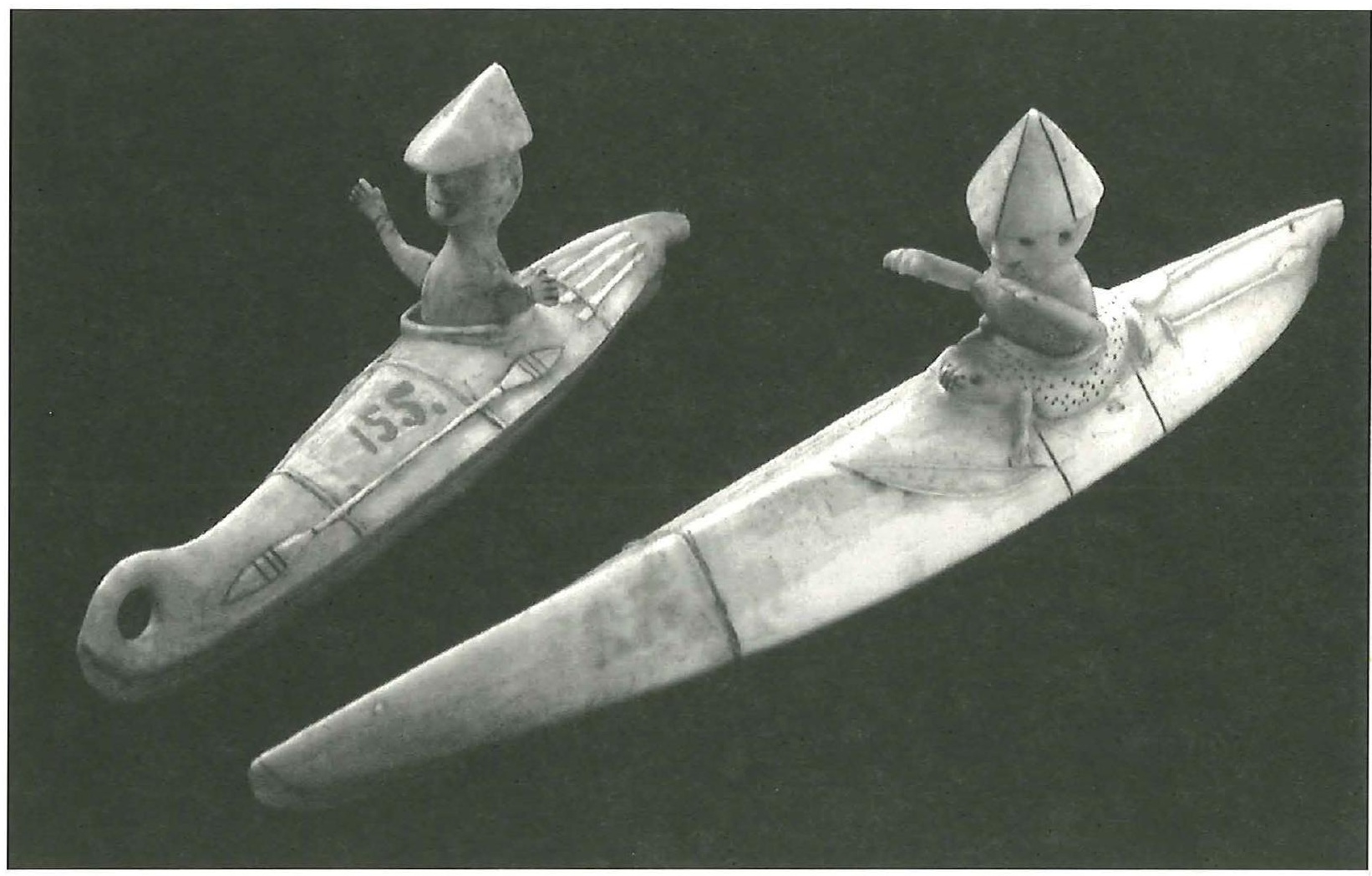

From the Etholén Collection, Yupik Eskimo Nushagák Basin. KVKL 6014.

evolution, which manifested one directional development in its simplest form. It was enforced by the increasingly widespread acceptance of a linear conception of time. In other words, it was thought that a culture develops along a straight path more or less without branches, in the same linear way as time was seen to flow.

From the perspective of today, it is hard to say whether the motive for Etholén's collecting activities was to promote the status of Finland as a representative of what was believed to be the culmination of evolution, Western Civilization, by comparing Finland to cultures which were believed to be primitive, that is, which were placed on the lower steps of the evolutionary pyramid by Western scientists. Alternatively, Etholén might just have been thrilled by the beauty of the strange objects. But as a representative of the mentality current at the beginning of the 19 th century, he can easily be seen as a man in a position to help the work of researchers. Most probably Etholén's ideas were comparable to those of the founders of Peter the Great's Museum (where Etholén sent most of his material), that is 
90 a belief in the educational programme of the Enlightenment and the scientific necessity of creating collections. Underlying this belief one can sense the rationalistic idea of reaching an understanding of man by studying material created either by nature or by man.

Researchers in the natural sciences strove consciously to create vast and perfect collections long before this trend towards completeness was popular in cultural studies and, even before the discipline of ethnology was born, although collecting of this kind in itself was not unfamiliar. Copying from the natural sciences, this precise type of collecting moved unquestioned and unreformed into the new disciplines of the humanities. And this brought with it the idea that the final answers were available through naming and grouping: by taxonomy and the classification of objects and phenomena. This idea which in its simplest form is associated with the power of language, not with picture-based memory aids as the former collections and cabinets of curiosities used to be, can be traced back at least to the Middle Ages in a way rather similar to that of the visual mnemothecnics. 'The power of language' here refers to the belief that naming things correctly gives you the right position for those things or ideas in the order of the universe and it constitutes the real meaning of the things. This belief has lived on in some conventions of the Western scientific world, and the discussion on this matter has received some interesting support even recently from the latest studies of consciousness. In visual mnemothecnics, on the other hand, the things were seen as the objectification of remembering ie. the aim of the objects was remembe- ring and thus collections automatically served as memorabilia much more far reaching in their effect than the objects which were there to be seen. Objects sort of de-materialized themselves to form ideas and symbols familiar to the active observer from other sources.

With this background and these links, no one questioned the objectivity of collecting in Etholén's time. Even afterwards, for a long time collecting activities were seen as belonging to almost the same category as the natural sciences, and museum collections enjoyed an equal neutral reputation. In the 17th century, criticism of the old ways of learning and remembering first emerged and understanding was placed in opposition to them. Then the meaning of collections was also seen differently and the basic idea of the way in which the former collections kept information was lost.

Maybe not surprisingly, in the rise of the modern sciences, the visitor to the museum was placed there as a student or a passive onlooker instead of the creator of new, personal ways of understanding the world. S/he gradually turned from explainer into listener. Later, when collecting and documenting techniques were developing as part of this natural historical attitude, it became more and more evident to researchers that the objects alone did not carry the needed information about the customs and cultures, of which they originally formed an essential part. Even the last phase, with the growth of the study of non-material forms of cultures in the fields of anthropology and ethnology in the 60 s, can be seen as part of 'a long forgetting' of the visual mnemotechnics of the Middle Ages in favour of the written 
language. Because of this basically rationalistic criticisim which the old museum collections received, the practice of collecting was viewed in the negative light by researchers for quite a time and there were almost no serious attemps to study the material already in the collections until very recently.

The Etholén collection is an important one for at least two museological reasons: it contains some rare or even unique pieces and early examples of interesting object groups and the collection constitutes the oldest part of the National Museum of Finland. The first objects sent by Etholén were exhibited as a study collection in the Academy of Turku (now the University of Helsinki) and they were destroyed in 1827 when almost the whole city of Turku burned to the ground. Soon after this destruction Etholén collected and sent new items to replace the lost material and these are the specimens represented in The Etholén Collection.

From the beginning of the 19th century missionaries were especially responsible for the growth of the Finnish ethnographical collections and some cultural areas are quite well documented by the systematic collecting organized by the National Museum. Otherwise the most expensive objects have usually come in the form of donations and Erickson's collection is one of the best examples of this.

\section{ERNEST ERICKSON}

Engineer Ernest Erickson was born in 1893 in Åland (an island area of Finland) and moved to the United States when he was thirty years old. He founded an agency called The Pulp Sales Corporation in New
York City and soon started to collect Native American artefacts receiving much help from George Heye, who in 1916 had founded one of the country's most important Indian museums based on his own collections (later named the National Museum of the American Indian, Smithsonian Institution, George Gustav Heye Center).

Erickson's collection contains typical material from the turn of the twentieth century. These artefacts are still common in Indian art galleries in the United States and on the international art market. Collectors have favoured and still particularly favour Southwestern blankets, silver ornaments and ceramics, Californian baskets and Northwest coastal woodwork. The most popular collector's items from the Great Plains area have been and still are beaded and quilled objects. Erickson's collection contains many interesting examples of all these artefacts.

One of the interesting aspects of Erickson's collection is the confrontation of Native and Euro-American traits in material culture, which can be seen in the objects in many ways. When Erickson started his collecting in the 1920s the Indian culture (Plains) was preserved/survived in living memory, with many people from the bison hunting era still active. Indians achieved citizenship of United States as late as 1924 and during most of the 20th century there have been cultural, political and even some armed confrontations with the Euro-American culture. Naturally arising from this, an interesting field of study would be the process of accepting and rejecting traits in material culture between different and in many ways opposing cultures or groups.

Native American material culture was at 
times directly influenced by European culture and occasionally, with the help of intertribal trade, even before the particular tribe made contact with Europeans in person. It is surprising how often the traits thought of as being most «Indian» are actually the result of European contacts, for example some of the birchbark works of Eastern woodland nations. Finnish settlers in Delaware had a great deal of cultural influence in this field. The floral beadwork traditions of Eastern Indians also developed hand in hand with EuroAmerican beadwork. Trade, war and migration made it possible for tribes in large areas of North America to get and make objekts quite similar in design and construction. It is possible to read from the objects and old photos, for example, that of all the Indian nations the Plains tribes of 19th century were admired not only by novelists and movie makers, but also by men from other Indian tribes. The Taos Pueblo, for example, wanted to promote their status by dressing like Plains Indians.

\section{TAKU WAKAN, THE BOOK}

The catalogue of Ernest Erickson's North American Indian collection was published in 1995 after a long and tedious process. Erickson shipped the first objects to Finland in 1947 on long-term loan. C. A. Nordman, the state archaeologist at that time, wrote a letter to Erickson thanking him for the loan and promising that a permanent ethnographical exhibition would be erected after a couple of years or so. The shipped objects would form an important part of the show, he wrote.

As Finland is still waiting for the "permanent exhibition» and the anthropological museum, items from Erickson's collection were exhibited over the years and finally the complete collection was shown in the National Museum during 19941995. This exhibition and the book mentioned above were the original conditions that Erickson stipulated for the National Museum to become the final owner of the objects.

The texts of the Taku Wakan catalogue were written by researchers Pirjo Varjola and Simo Hankaniemi. Varjola also compiled part of the volume on The Etholén Collection. She has worked in the Finnish National Museum's ethnological collections since 1958 organizing exhibitions and writing books and articles on the collections. Simo Hankaniemi specializes in the cultures of the Great Plains area, carrying out research especially on their weapons and modes of warfare. He has organized several exhibitions of Plains Indian culture around Finland and written articles on related subjects.

The layout of the book Taku Wakan is quite light and pleasing, and it is clear that the catalogue was made not only for experts but for the general reader as well: the coloured pictures are large and the texts are mostly easy to read. On some pages unfortunately the photographs and texts are not in a logical order, which is somewhat disturbing. A reader will naturally connect a picture with text closest to it, as happens in most, but not all, of the book.

There are of course some printing 


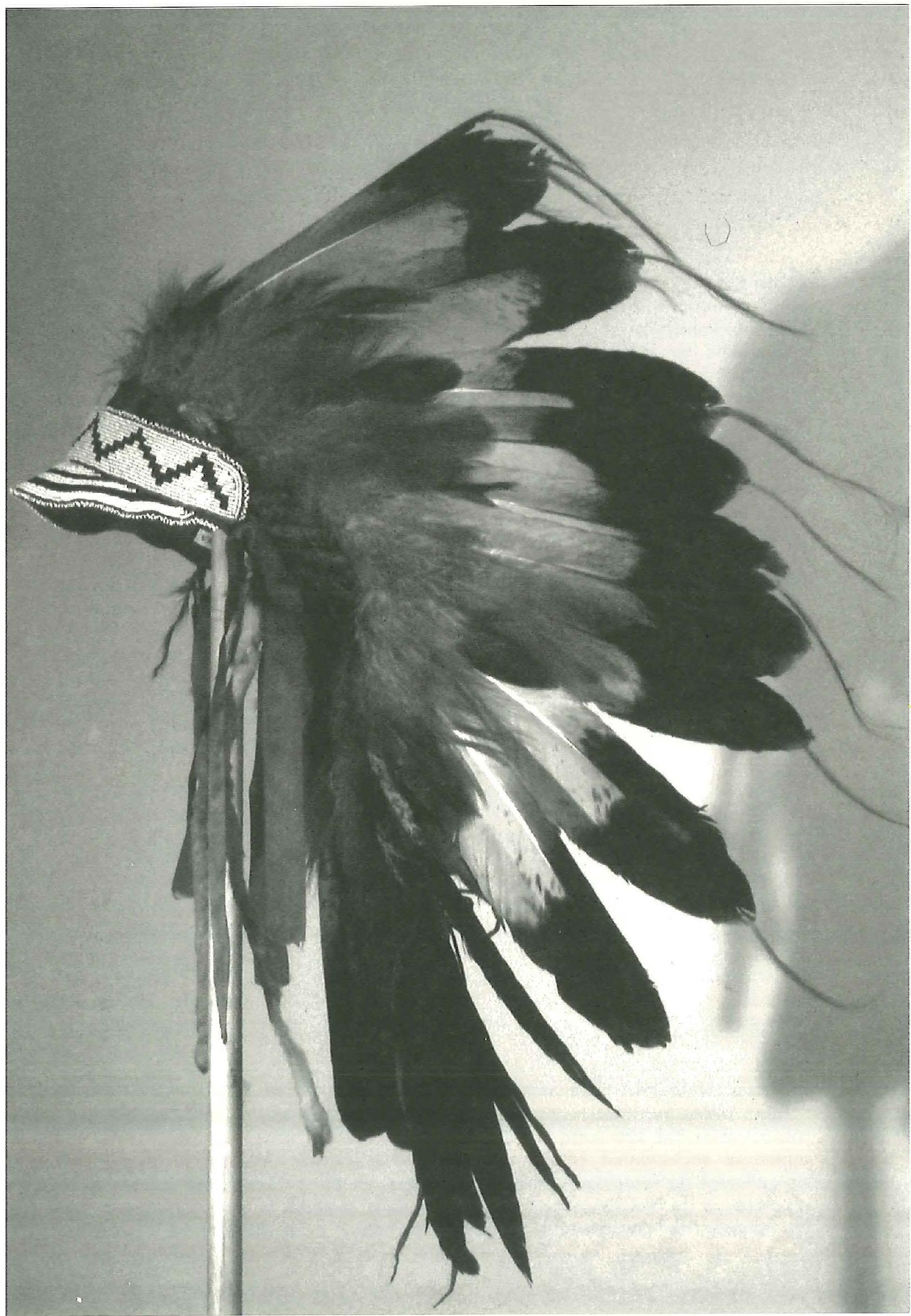


94 errors, but they do not hinder understanding. However, the publication date of Simo Hankaniemi's article on Plains shields should be changed from 1933 to 1994 (Helsingin yliopiston taidehistorian laitoksen julkaisuja XII). On page 197 there is a photograph taken in Alaska, while the objects discussed in the text are from the Northeastern forests. In other cases the old black and white photographs nicely supplement those of the catalogue photos and they are not those most frequently published in so many books on North American Indians.

In the book the artefacts are divided into cultural areas and each area is introduced with a short text which deals with the most important aspects of the way of life. Not only material culture but ecology and spiritual culture are discussed, thus little space was available for the historical perpective. Concentrating on approximately the same historical period as when the objects were made was a solution of a kind to this problem. This however was not overtly stated and there is a risk that there will be a misunderstanding, getting the impression of a timeless, ahistorical way of life. This problem is indeed common in writing about other cultures and is especially common in a catalogue such as this. Apart from this, the texts in this particular book manage for the most part to convey the essential facts and impressions of the cultures. Some texts are even quite strong in their generalization of the cultures.

Taku Wakan introduces not only the cultural areas but also some of the most important sociocultural phenomena, to have affected the formation of the material cultures of the North American Indians, for example the Potlatch of the North- western coast nations. The catalogue also gives more information on the individual objects than is usual in museum catalogues: the materials and manufacturing techniques of each individual item are described. Techniques used generally, such as basketmaking and ceramics have their own special articles, but need drawings and photographs to clarify the details. The text alone does not always explain enough. This difficulty is of course partly mitigated by recommendations for further reading.

Because Erickson's collection was compiled from a variety of sources not directly from the native context, and because of the intervention of middlemen, little information accompanies the items concerned. The researchers had to combine intellectual guesswork with their knowledge of the raw materials and stylistic preferences of individual tribes to date and place the artefacts.

The text of the catalogue is mainly in Finnish, but some brief information about the objects is also given in English. The Finnish version of the text is particulary interesting in its scientific speculation but unfortunately the English version is too short to accommodate that. Perhaps these short descriptions are enough for experts but in some cases a general reader would like to have more. About the Finnish text one can say that not so many readers are familiar with such old words as telso (a carving tool) or ruoju (ankle flap of a shoe or moccasin). But in general the writers do not disturb the reader by using ethnological jargon.

For research purposes it would have been useful to have some references to similar material in other collections. But perhaps it is too much to ask as there are 
so few complete catalogues of collections available from the same period. The lack of catalogues seems to be at least partly a result of the attitude that Native American objects belong rather to the collecting and antique markets than to the material cultures and history of the nations in question.

\section{THE BOOK OF \\ THE ETHOLENN COLLECTION}

The Etholén Collection was published in its entirety in English in 1990 for the international market. The book is a joint venture between researchers from the Soviet Union and the National Museum of Finland. It contains biographical entries on the collectors who worked in Russian ruled Alaska during the early 19th century, and gives details of 559 artefacts which were taken from Alaska to Finland.

Carefully selected photographs of details of the artefacts make the book especially valuable for researchers with an interest in the material cultures of the Alaskan nations. The number of photographs also make it helpful for «experimental anthropologists" and others who want to make reproductions of the objects.

Biographical research has been carried out in both Finnish and Russian archives and without this co-operation between the researchers of the two countries the book would have been much poorer. The identification of artefacts and the establishment of their origins was facilitated by the fact that the Finnish Alaska collection originally formed part of the massive Russian collections with their systematic catalogues and other documentation, including surviving freight lists.

The comparative studies of letters, notes and objects have produced much new ry meaning of the word, heavier than Taku Wakan and the Etholén Collection Catalogue belongs more clearly in the class of pure scientific catalogues than its younger competitor.

Even during the 17th century there were tens of thousands of artefacts from North America in European collections. Most of the items were everyday utensils: clothing, tools and weapons, musical instruments or decorative objects made of wampum shell beads. These objects were curiosities for the European viewer, because of their rarity. But many of the collections also had something of a scientific profile connected to rationality and natural historical thinking. By making comparative studies between the utensils which were used in various areas, Europeans tried to acquire a knowledge of the world, to achieve a holistic understanding of our mostly unknown visible and unvisible surroundings.

We have not yet achieved anything close to a complete knowledge of the Native American artefacts collected in Europe during the last five centuries. The publication of the Etholén and Erickson collection catalogues by the National Museum of Finland is part of the work of completing the picture. These catalogues tell us about different ways of accumulating a museum collection and also about different ways of approaching more closely and representing another culture. The Etholén Collection was put together perhaps in a rather naive belief in objective research and for the purpose of providing a perfect picture of the Alaskan cultures. Erickson's collection on the other hand reveals to us 
96 what was thought to represent the arts of the turn of the century natives of the USA. These two collections show a rather more multi-faceted picture of North America, while simultaneously breaking the stereotype of another culture, which is created if only its finest pieces are exhibited.

In museum work the mystique of ageing is always present. It is usually never questioned whether the value of individual items will really increase over the years, as similar objects become exceptional. For this reason the Etholén collection has long been valuable because the objects presented are older and more unique than Erickson's material. The items give an extra value to the book as well. But the Erickson collection will also gain more status as time goes by, and with it the book Taku Wakan; the more so because the collection itself, the objects and the time they were collected are relatively contemporaneous.

Both books, Taku Wakan and The Etholén Collection are great works when compared to anything else done in Finland in the field of North American ethnology. As these books have accurate texts and good photographs, there is less need to examine the originals. For international researchers this kind of book is essential. As a researcher one can only hope that in the future all the artefacts of every museum will be available on the Internet or in catalogues like these.

For the general reader these kinds of catalogues mean a more multifaceted knowledge. The books tell about material cultures compiled during different historical periods using different methods: a Russian governor general Etholén organi- zed collecting for research purposes in Alaska, and collector Erickson valued the artefacts for their esthetic appearance. For all the above mentioned reasons both catalogues are interesting and at the same time nicely complementary. Neither book makes any analysis of the value of the whole collections, from the documentor's or from the collector's view. The books leave these considerations together with many other paths to explore to the reader, as good catalogues should do.

Anne Aurasmaa, researcher, Finnish Academy,
University of Helsinki
Adr: 8 Winterbourne Road, Thornton Heath,
Surrey, CR7 7QT, UK
Fax +44-1812519598

Pirjo Varjola \& Simo Hankaniemi, Taku Wakan. The Ernest Erickson Collection of North American Indian Art in the National Museum of Finland. National Board of Antiquities collection catalogue 1. Helsinki, National Board of Antiquities, 1995. ISBN 951-9075-82-8. 206 pp. 1 drawing, 8 maps, 189 col.illust. and 18 b \& w. illust. FIM 220 .

Pirjo Varjola et al., The Etholén Collection. The ethnographic Alaskan collection of Adolf Etholén and his contemporaries in the National Museum of Finland. Helsinki, National Board of Antiquities, 1990. ISBN 951-9075-42-9. 336 pp. 21 drawings, 11 maps, 184 col.illust. and 402 b \& w. illust. FIM 250. 